\title{
Time Series Deformation Monitoring over Large Infrastructures around Dongting Lake Using $X$-Band PSI with a Combined Thermal Expansion and Seasonal Model
}

\author{
Liang Bao $\mathbb{D}^{1,2}$ Xuemin Xing $\mathbb{D}^{1,2}$ Lifu Chen $\mathbb{D}^{1,3}$ Zhihui Yuan $\mathbb{D}^{1,3}$ Bin Liu $\mathbb{D}^{1,2}$ \\ Qing Xia $\mathbb{C}^{1,2}$ and Wei Peng $\mathbb{1}^{1,2}$ \\ ${ }^{1}$ Laboratory of Radar Remote Sensing Applications, Changsha University of Science \& Technology, Changsha 410014, China \\ ${ }^{2}$ School of Traffic and Transportation Engineering, Changsha University of Science \& Technology, Changsha 410014, China \\ ${ }^{3}$ School of Electrical and Information Engineering, Changsha University of Science \& Technology, Changsha 410014, China \\ Correspondence should be addressed to Xuemin Xing; xuemin.xing@csust.edu.cn
}

Received 26 November 2020; Revised 5 March 2021; Accepted 10 March 2021; Published 31 March 2021

Academic Editor: Zhenxing Zhang

Copyright (C) 2021 Liang Bao et al. This is an open access article distributed under the Creative Commons Attribution License, which permits unrestricted use, distribution, and reproduction in any medium, provided the original work is properly cited.

\begin{abstract}
The long-term spatial-temporal deformation monitoring of densely distributed infrastructures near the lake area is of great significance to understand the urban health status and prevent the potential traffic safety problems. In this paper, the permanent scatterer interferometry (PSI) technology with TerraSAR-X imagery over the area around Dongting Lake was utilized to generate the long-term spatial-temporal deformation. Since the X-band SAR interferometric phases are highly influenced by the thermal dilation of the observed objects, and the deformation of large infrastructures are highly related to external temperature, a combined deformation model considering the thermal expansion and the seasonal environmental factors was proposed to model the temporal variations of the deformation. The time series deformation and the thermal dilation parameter over the area were obtained, and a comparative study with the traditional linear model was conducted. The Dongting Lake Bridge and the typical feature points distributed around the lake were analyzed in details. In order to compensate for the unavailability of external in situ measurements over the area, phase residuals and the subsidence generated through Differential Interferometric Synthetic Aperture Radar (D-InSAR) were utilized to verify the accuracy of the obtained deformation time series. Experiment results suggested that the proposed model is suitable and suggested for the selected study site. The root mean square error (RMSE) of the residual phase was estimated as $0.32 \mathrm{rad}$, and the RMSE compared with D-InSAR derived deformation was $\pm 1.1 \mathrm{~mm}$.
\end{abstract}

\section{Introduction}

Dongting Lake is located at the South Bank of Yangtze River in the north of Hunan Province, China, which is a tectonic lake with the characteristics of barrier lake. With the welldeveloped surrounding water system, Dongting Lake is adjacent to Yangtze River to the north, with its river water flowing into the Xiang River. Yueyang is a lakeside city of Hunan Province next to Dongting Lake, which is under the combined geological structure characteristics of intermittent uplift denudation and intermittent stable uplift deposition (i.e., uplift and stable alternating) [1]. As a city with a population of 5.8 million, plenty of residential areas and developed transportation network are distributed in Yueyang. Every flood season, the residential areas around Dongting Lake are under high potential danger of accumulated deformation, collapse of ground surface, or even landslides of the slope, which greatly endangers the safety of the area. The stability control of the densely distributed infrastructures near the Lake area is of remarkable importance. Therefore, the longterm spatial-temporal deformation monitoring over this area is of great significance to understand its health status and prevent the potential traffic safety problems.

Permanent scatterer interferometry (PSI) has proven to be an effective tool to obtain time series deformation results through extracting and processing those PS points, which can always keep long-term stable backscatter characteristics over multi-SAR images [2]. It can detect information of 
ground displacement with millimeter precision, showing high potential ability for the application to large traffic infrastructures (i.e., railways, highways, and bridges) [3-6]. Earlier study shows that bridge railings, curbs, and pavements can be treated as artificial corner reflector structures, which are easily to be identified as PS points in SAR images [7]. Successful cases also proved the applicability using PSI technology with high-resolution SAR images to monitor slow deformation of large-scale bridges and other artificial structures $[8,9]$.

Deformation modeling determines the functional relationship between the displacement phase component and deformation parameters at each high coherence point. The deformation model not only determines the accuracy of displacement estimation but also directly affects the subsequent progress such as phase unwrapping and the interpretation of the final deformation results [10]. Earlier studies showed that the linear model (LM) is the most commonly used temporal model in PSI processing, which has been successfully applied in a large amount of cases $[11,12]$. However, the deformation over large infrastructures (especially bridges) is related to complicated factors, such as the pile foundation, steel structure, and bridge cable, which are highly influenced by external temperatures [13]. Specifically, the upward accumulative effect of the thermal expansion can counteract the downward movement caused by land subsidence, which leads to the underestimation of land subsidence estimation [14]. Moreover, as introduced in [15], the X-band SAR interferometric phases are highly influenced by the thermal dilation of the observed objects. The thermal component of a given interferogram shows the displacement caused by thermal dilation, which is a consequence of temperature differences in the imaged area between two SAR acquisitions. These factors have a clear impact on the deformation velocity map. In particular, these factors can be remarkably severe if the observed period is relatively short (e.g., less than a year) [16]. Moreover, considering that the deformation of steel bridges is highly related to external temperature, some researchers introduced the thermal expansion model into the deformation estimation of large infrastructures [17-19].

Based on the above background, considering the unavoidable influences by the thermal dilation of the observed objects for X-band SAR images and the special hydrological environment of Donting Lake area, the thermal expansion and the participation were introduced into the seasonal model (TESM), which are used to model the lowpass components in PSI. With use of 24 high-resolution TerraSAR-X images acquired from December 2011 to April 2013, covering the area around Dongting Lake, two groups of time series deformation results, generated by both LM and TESM, have been obtained. Subsequently, a comparative investigation between the two deformation sequences was conducted, and the time series deformation results of Dongting Lake Bridge were analyzed in detail.

\section{Methods}

2.1. Standard LM of PSI. A master image should be selected from the time series SAR images in the experiment, and then all the slave images are coregistered and resampled to the master image. An external SRTM DEM data is utilized to remove the topographic phase and, consequently, phase filtering, and temporal-spatial unwrapping is carried out for each interferometric pair.

For each baseline in the PS network (connecting $i$-th and $j$-th PS candidates), the interferometric phase difference can be expressed as [20]

$$
\Delta \phi_{i, j}^{m}=2 \pi \Delta k_{i, j}^{m}+\frac{4 \pi}{\lambda} \cdot \frac{B_{\perp}^{m}}{R_{i, j}^{m} \sin \theta_{i, j}^{m}} \cdot \Delta \delta H_{i, j}+\frac{4 \cdot \pi \cdot t^{m}}{\lambda} \Delta v_{i, j}+\Delta \phi \mathrm{res}_{i, j}^{m},
$$

where $m$ represents the index number of the interferometric pair, $\Delta \phi_{i, j}^{m}$ and $\Delta k_{i, j}^{m}$ are the differences of the interferometric phase and the integer phase ambiguity between neighboring PS targets, respectively, $\Delta v_{i, j}$ defines the increments of linear displacement rates along the line of sight (LOS), and $\Delta \delta H_{i, j}$ represents the increment of elevation error. $t^{m}$ and $B_{\perp}^{m}$ represent the temporal baseline and normal baseline of the $m$-th interferogram, respectively, $R_{i, j}^{m}$ defines the slant range distance, and $\theta_{i, j}^{m}$ defines the incident angle; $\Delta \phi$ res $_{i, j}^{m}$ is the residual phase, including the contribution of atmospheric delay phase, decorrelation noise, and high-pass deformation component.

According to formula (1), $\Delta k_{i, j}^{m}, \Delta \delta H_{i, j}$, and $\Delta v_{i, j}$ are unknown. The LAMBDA (Least Squares Ambiguity Correlation Adjustment) method proposed by Teunissen of Delft University in the Netherlands for the GPS dual differential phase observation model can be used here to unwrap the temporal differential phases [21]. This technique was introduced into InSAR processing to search the integer ambiguity in PSI in 2003 [22]. In order to ensure the accuracy of the temporal unwrapping results, it is necessary to evaluate the quality of each PS points and delete those of poor quality. We choose baseline correlation coefficient as the baseline accuracy index, which was introduced by Ferretti $[20,23]$. It can be written as

$$
\gamma_{\text {base }}=\frac{1}{n} \sum_{i=1}^{n}\left(\cos \left(\Delta w_{i}\right)+j \sin \left(\Delta w_{i}\right)\right)
$$

where $n$ is the total number of baselines, and $\Delta w_{i}$ is the residual phase for each baseline (equals to $\Delta \phi$ res $_{i, j}^{m}$ in equation (1)).

The absolute deformation rate and elevation error at each PS points are calculated through spatial phase unwrapping. The specific processing flow is shown in Figure 1.

2.2. Seasonal Model of PSI. The seasonal model supposes the low-pass component as the sum of the linear and periodic subsidence, which has been widely used in describing the deformation related to seasonal factors. Seasonal model can be written as [24] 


$$
\begin{aligned}
\Delta \phi_{i, j}^{m}= & 2 \pi \Delta k_{i, j}^{m}+\frac{4 \pi}{\lambda} \cdot \frac{B_{\perp}^{m}}{R_{i, j}^{m} \sin \theta_{i, j}^{m}} \Delta \delta H_{i, j}+\frac{4 \pi}{\lambda} \Delta t^{m} \Delta v_{i, j} \\
& +\frac{4 \pi}{\lambda}\left[\Delta A_{i, j} \cos \left(\frac{2 \pi}{T} t^{m}\right)+\Delta B_{i, j} \sin \left(\frac{2 \pi}{T} t^{m}\right)\right]+\Delta \phi \text { res }_{i, j}^{m}
\end{aligned}
$$

where $T$ defines the seasonal deformation period ( $T=365$ days); $\Delta A_{i, j}, \Delta B_{i, j}$, and $\Delta v_{i, j}$ are the unknown parameters.

2.3. Extended TESM of PSI. The TESM introduces the thermal expansion component into the seasonal model, which can be written as:

$$
\begin{aligned}
\Delta \phi_{i, j}^{m}= & 2 \pi \Delta k_{i, j}^{m}+\frac{4 \pi}{\lambda} \cdot \frac{B_{\perp}^{m}}{R_{i, j}^{m} \sin \theta_{i, j}^{m}} \Delta \delta H_{i, j}+\frac{4 \pi}{\lambda} \Delta \operatorname{Temp}^{m} \Delta T h_{i, j} \\
& +\frac{4 \pi}{\lambda} \Delta \operatorname{Prec}^{m} \Delta P_{i, j}+\frac{4 \pi}{\lambda} \Delta t^{m} \Delta v_{i, j}+\frac{4 \pi}{\lambda} \\
& \cdot\left[\Delta A_{i, j} \cos \left(\frac{2 \pi}{T} t^{m}\right)+\Delta B_{i, j} \sin \left(\frac{2 \pi}{T} t^{m}\right)\right]+\Delta \phi \text { res }_{i, j}^{m},
\end{aligned}
$$

where $\Delta \mathrm{Temp}^{m}$ and $\Delta \operatorname{Prec}^{m}$ are the differential temperature and precipitation between the two SAR image acquisitions of the $m$-th interferogram, respectively, and $\Delta T h_{i, j}$ and $\Delta P_{i, j}$ are the increments of the thermal dilation parameter and the precipitation coefficient between the two adjacent PS targets separately. The unknown parameters in equation (4) are extended as $\Delta k_{i, j}^{m}, \Delta \delta H_{i, j}, \Delta A_{i, j}, \Delta B_{i, j}, \Delta P_{i, j}, \Delta v_{i, j}$, and $\Delta T h_{i, j}$. It can be seen from equation (4) that the interferometric phase varies linearly with the unknown parameters. Therefore, similar algorithms as introduced in equation (1) can be utilized to solve the unknown parameters. Subsequently, the lowpass (LP) deformation component at each target can be obtained. Considering that the atmospheric delay phase component is a temporally random high frequency signal, it is spatially related to low frequency signal. In contrast, the nonlinear residual deformation phase is a high frequency signal both spatially and temporally [25]. Accordingly, in order to extract the high-pass (HP) deformation component from the residual phase, a temporal HP filtering and a spatial LP filtering can be utilized [23]. Through summarizing the LP and HP deformation components, the final time series deformation at each PS point can be acquired.

\subsection{Experiment}

2.4.1. Geological Background of the Study Area. The surrounding area of Dongting Lake was selected as the study area. As a city with a population of 5.8 million, plenty of residential areas and developed transportation network are distributed in Yueyang. Hangzhou-Ruili Expressway, passing through Dongting Lake Bridge and Dongting Lake super bridge, is an important transportation hub connecting Junshan district and Yueyang Tower District in the northwest of Yueyang City. Dongting Lake Bridge is located at the downstream of Northern Gate Ferry in Yueyang City, which

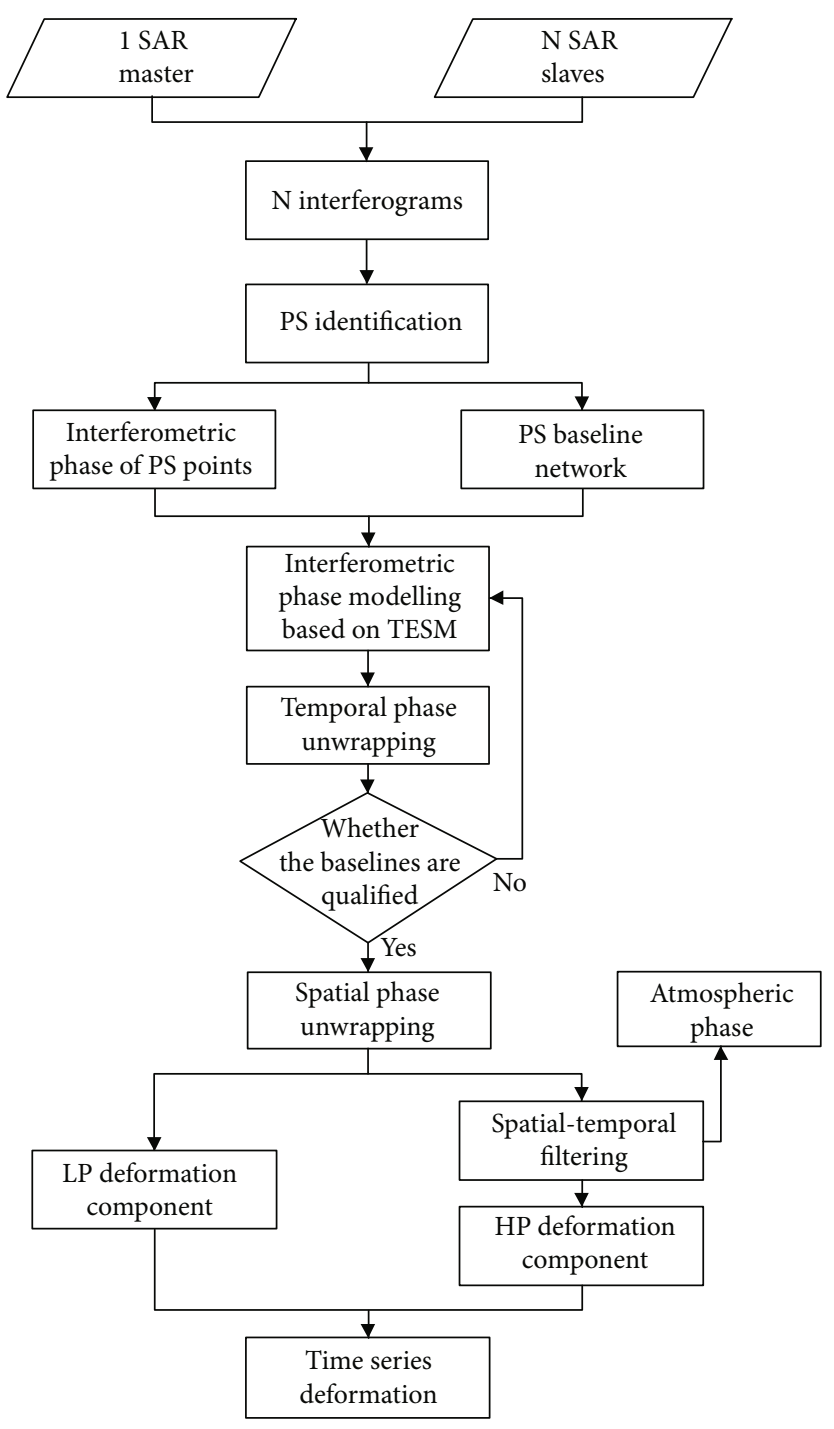

FIGURE 1: PSI data processing flow chart.

was built on 19 December 1996, and opened to traffic on 26 December 2000. As an urban expressway connecting Junshan district and Yueyang Tower District, Dongting Lake Bridge is a super huge bridge crossing Dongting Lake on the North Hunan trunk line. With a total length of $5784.5 \mathrm{~m}$, the width of the main water level of Dongting Lake bridge is about $1400 \mathrm{~m}$. Equipped with a $10 \times 50 \mathrm{~m}$ continuous box girder, it is an $880 \mathrm{~m}$ long-span cable-stayed bridge with three towers and a double inclined-plane cable floating system. Three tower long-span cable-stayed bridge is the first structural form adopted in China, which is the most important structural characteristic of Dongting Lake Bridge [26].

The spatial coverage of the selected TerraSAR-X image is outlined by red rectangle in Figure 2(a). The green rectangle in Figure 2(b) defines the test area of Donting Lake of interest in our experiment. The location of Dongting Lake Bridge with the average amplitude image as background is shown in Figure 2(b). The territory of China is shown in Figure 2(c), and the in situ picture of the bridge is shown in Figure 2(d). According to our in situ geological investigation, the surface water system around Dongting Lake Bridge is 


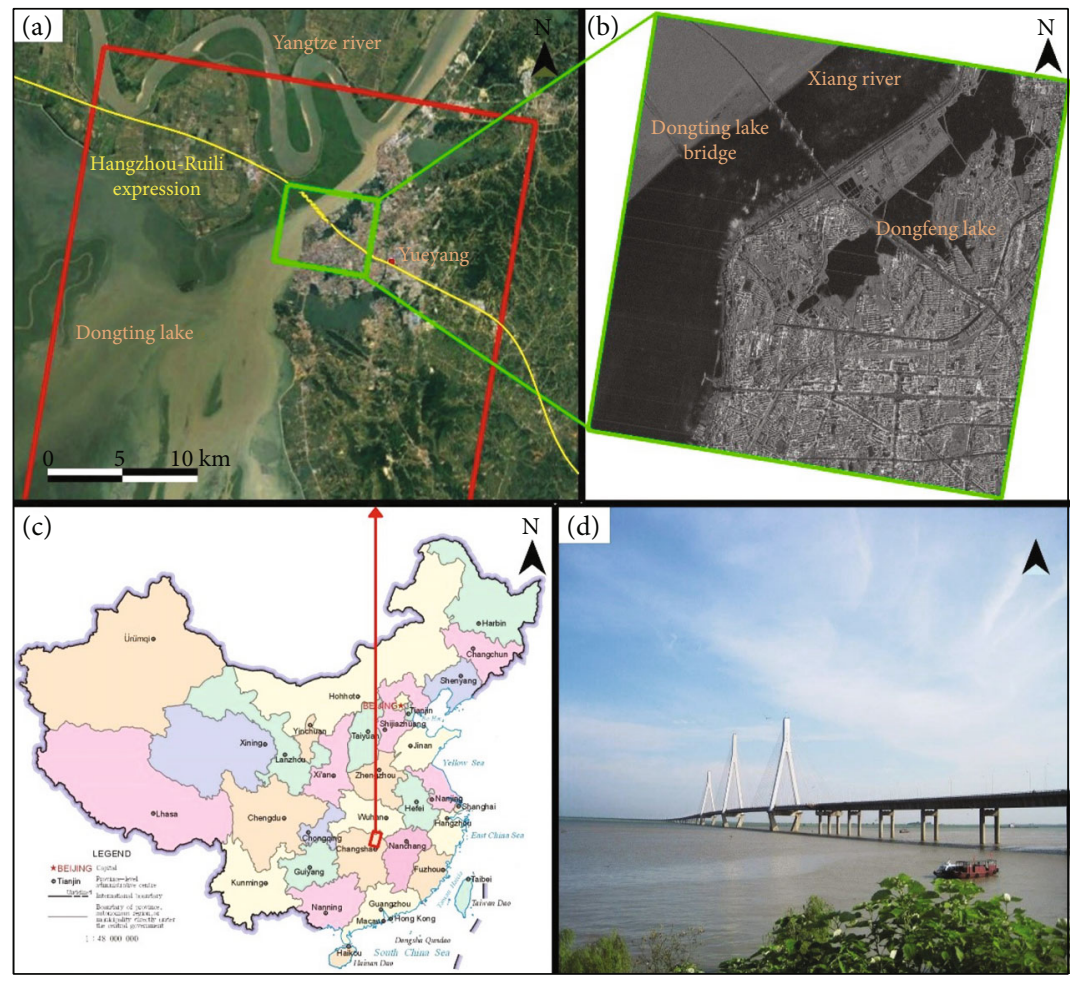

Figure 2: Study area features at different scales: (a) regional scale in China, (b) an amplitude image of the study area, (c) location of the study area in China, and (d) in situ picture of Dongting Lake Bridge.

developed, and the aquifer is extensive, which is prone to subsidence. Therefore, the long-term deformation monitoring of this area is of great significance.

2.4.2. SAR Acquisition and Data Processing. In this paper, 24 TerraSAR X-band Stripmap descending images covering Dongting Lake Bridge from December 2011 to April 2013 were collected (the parameters of these images are listed in Table 1). The pixel spacing of selected images is $1.364 \mathrm{~m}$ along the range direction and $1.849 \mathrm{~m}$ along the azimuth direction. The polarization mode of these images is $\mathrm{HH}$ polarization. The radar processing module of Sarscape 5.2 was used for the interferometric processing. In order to conduct a more precise observation over the bridge, no multilooking was conducted to constrain the original resolution. And the 9-th image in Table 1 represents the selected master image, whereas the rest ones are slave images. In the interferometric processing, the topographic phase was eliminated with use of SRTM DEM data (with $30 \mathrm{~m}$ spatial resolution provided by NASA). The orbit error is removed by the polynomial fitting method [27]. Thus, 23 differential interferograms are generated without spatial-temporal phase unwrapping.

According to equation (4), in order to model the thermal expansion phase component, the differential temperature and the differential precipitation of the interferometric period are necessary. The external air average temperature of Yueyang City is shown in Figure 3 (obtained on the website of China Meteorological Administration [28]), which was treated as the surface temperature in equation (4). The
TABLE 1: List of the interferometric pairs and their parameters with image number 9 as the master (strip no. 011, descending).

\begin{tabular}{|c|c|c|c|}
\hline $\begin{array}{l}\text { Image } \\
\text { no. }\end{array}$ & $\begin{array}{l}\text { Acquisition dates } \\
\text { (yyyy/mm/dd) }\end{array}$ & $\begin{array}{c}\text { Temporal baseline } \\
\text { (days) }\end{array}$ & $\begin{array}{c}\text { Normal } \\
\text { baseline }(\mathrm{m})\end{array}$ \\
\hline 1 & $2011 / 12 / 28$ & -264 & -95 \\
\hline 2 & $2012 / 2 / 10$ & -220 & -26 \\
\hline 3 & $2012 / 3 / 3$ & -198 & -100 \\
\hline 4 & $2012 / 3 / 25$ & -176 & -17 \\
\hline 5 & $2012 / 4 / 16$ & -154 & 35 \\
\hline 6 & $2012 / 5 / 8$ & -132 & 58 \\
\hline 7 & $2012 / 5 / 30$ & -110 & 58 \\
\hline 8 & $2012 / 8 / 26$ & -22 & 61 \\
\hline 9 & $2012 / 9 / 17$ & 0 & 0 \\
\hline 10 & $2012 / 10 / 9$ & 22 & -145 \\
\hline 11 & $2012 / 10 / 31$ & 44 & 16 \\
\hline 12 & $2012 / 11 / 11$ & 55 & 52 \\
\hline 13 & $2012 / 11 / 22$ & 66 & -32 \\
\hline 14 & $2012 / 12 / 14$ & 88 & 144 \\
\hline 15 & $2012 / 12 / 25$ & 99 & 3 \\
\hline 16 & $2013 / 1 / 5$ & 110 & -71 \\
\hline 17 & $2013 / 1 / 16$ & 121 & -38 \\
\hline 18 & $2013 / 1 / 27$ & 132 & -94 \\
\hline 19 & $2013 / 2 / 7$ & 143 & 70 \\
\hline 20 & $2013 / 2 / 18$ & 154 & -47 \\
\hline 21 & $2013 / 3 / 1$ & 165 & -206 \\
\hline 22 & $2013 / 3 / 12$ & 176 & -120 \\
\hline 23 & $2013 / 3 / 23$ & 187 & 133 \\
\hline 24 & $2013 / 4 / 3$ & 198 & -125 \\
\hline
\end{tabular}




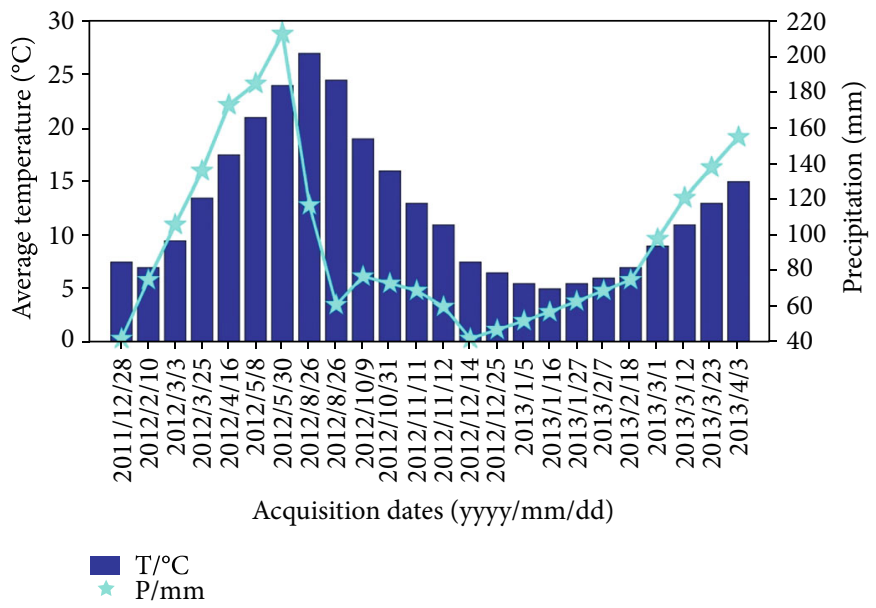

FIgURE 3: The average temperature and precipitation of Yueyang city (from 28 December 2011 to 3 April 2013).

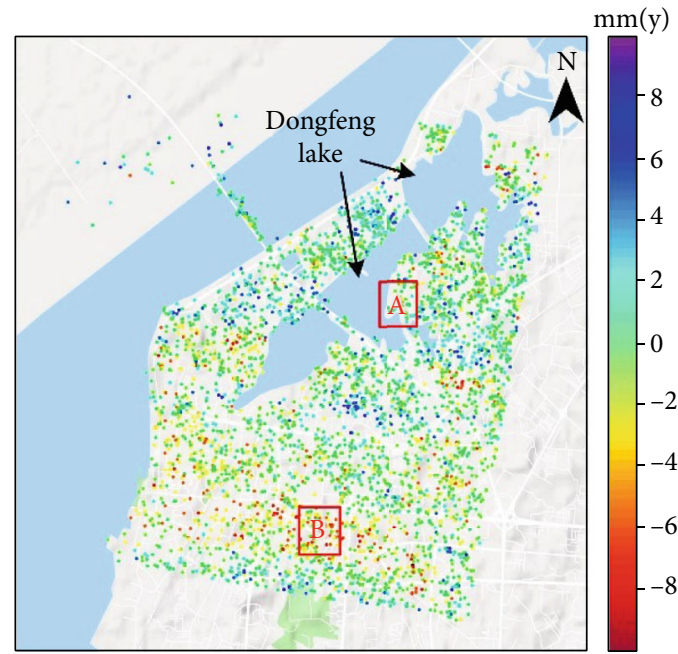

(a)

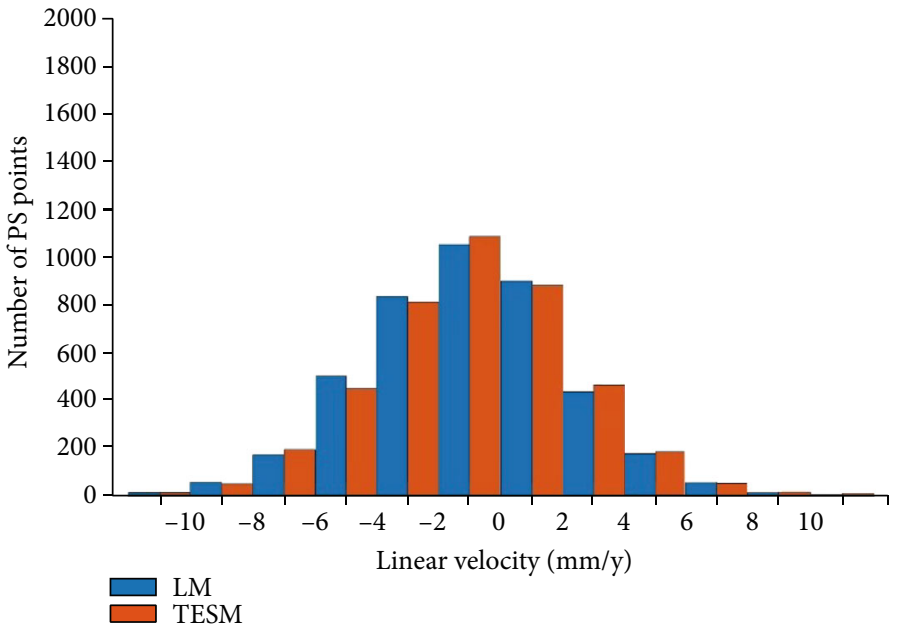

(b)

FIGURE 4: (a) Linear velocity map generated by TESM (with Google map as background). (b) PS point distribution comparison of the deformation velocity for the two models.

processes including the PS recognition [29], PS baseline network construction, parameter estimation, and time series deformation generation were conducted by the MATLAB software. 4420 PS points and 9224 triangle network baselines were generated.

\subsection{Experimental Results}

2.5.1. Linear Deformation Velocities. Two groups of experiments for both two models were carried out, with two groups of deformation parameters generated, respectively. The average linear velocities were generated by the TESM (Figure 4(a)). And the comparison for the number of the PS point distribution for the two models is shown in Figure 4(b). All the geocoded results in this paper were transferred to the vertical direction according to $S_{v}=S_{\mathrm{LOS}} / \cos \theta$, where $S_{v}$ and $S_{\text {LOS }}$ represent the vertical and LOS subsidence, respectively.
According to our experiment, the experimental results show that the PS number distribution of the two models shows good consistency (Figure 4(b)). The results show that the linear velocity of TESM is consistent in the spatial distribution,and the deformation rate is generally between $-2 \mathrm{~mm} /$ year and $-10 \mathrm{~mm} /$ year, the maximum deformation rate is $-13 \mathrm{~mm} /$ year, and the color range is from yellow to orange. The model has a slight uplift point near the Dongfeng Lake, and its velocity is mainly between $2 \mathrm{~mm} /$ year and $6 \mathrm{~mm} /$ year. It is considered that the uplift is related to the geological structure and terrain type of Jianghan-Dongting Basin where Yueyang City is located. This area is located in the margin of the geological structure between Yuanjiang depression and Fushan uplift [1]. In order to further analyze the results, two main deformation regions (red rectangles $\mathrm{A}$ and B in Figure 4(a)) are extracted. The uplift rate of area A is $8 \mathrm{~mm} /$ year. In contrast, area B is dominated by subsidence, and the maximum subsidence rate is $13 \mathrm{~mm} /$ year. The total 

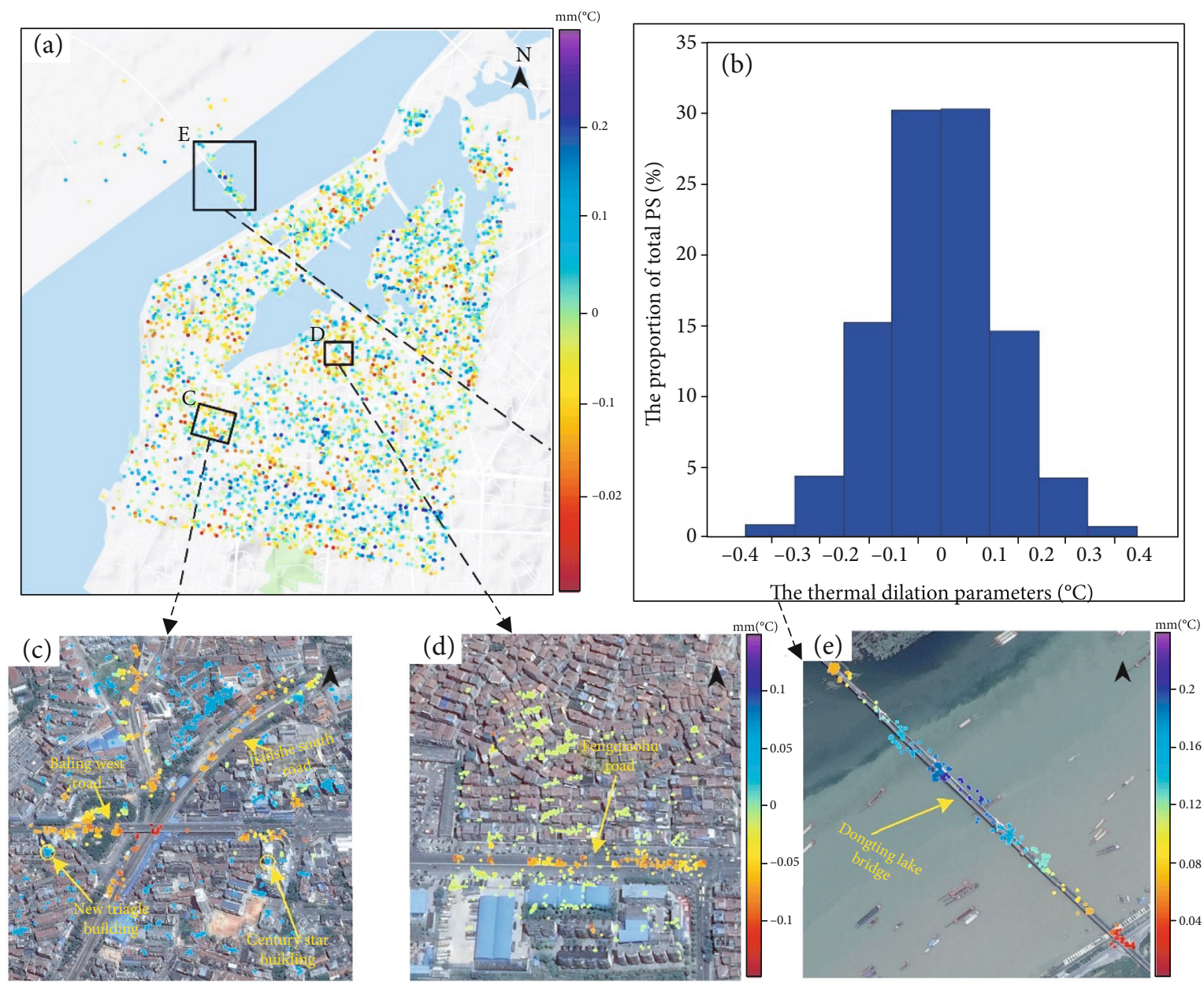

Figure 5: (a) Thermal dilation parameter map. (b) The proportion of thermal dilation parameter distribution on PS targets. (c), (d), and (e) are enlarged maps of area C, D, and E in Figure 5(a) (with optical image as background).

average deformation velocity of Dongting Lake Bridge is $-5 \mathrm{~mm} /$ year.

2.5.2. Thermal Map. The obtained thermal dilation parameters in equation (4) are shown in Figure 5(a). It can be seen that the points within rectangle $\mathrm{C}$ were with relatively higher values, with the maximum value of $0.3 \mathrm{~mm} /{ }^{\circ} \mathrm{C}$. The suggested reason is related to the heights of the infrastructures in this area. According to equation (5) introduced in [16] (which will be described later), with a constant thermal expansion (considered constant when different infrastructures are made of similar materials), the thermal dilator parameter is directly proportional to the height of the buildings. The quantitative distribution of all the thermal dilation parameters is shown in Figure 5(b). It is easy to find that the values for $60 \%$ of PS points ranged within the interval of $\left[\begin{array}{ll}-0.1 & 0.1\end{array}\right] \mathrm{mm} /{ }^{\circ} \mathrm{C}$, whereas $90 \%$ of PS points within the interval of [- $\begin{array}{ll}-0.2 & 0.2]\end{array}$ $\mathrm{mm} /{ }^{\circ} \mathrm{C}$ and $98 \%$ of PS points within the interval of $[-0.3$ $0.3] \mathrm{mm} /{ }^{\circ} \mathrm{C}$. As our in situ investigation, the typical buildings distributed in $\mathrm{C}$ are the New Triangle Building and the Century Star Building, both of which were with higher height (as shown in Figure 5(c)). According to our estimation, the highest thermal dilation parameter in area $\mathrm{C}$ was the Century Star Building, with a value of $0.17 \mathrm{~mm} /{ }^{\circ} \mathrm{C}$, which was supposed to be made of quartzite aggregate cement concrete. In contrast, area D shown in Figure 5(a) near Dongfeng Lake in the north was mainly distributed with old residential areas and hotels (the enlarged map is shown in Figure 5(d)). With a lower height, the thermal dilation parameters over this area were relatively low or even negative (the mean thermal dilation parameter of Fengqiaohu Road is estimated as $-0.12 \mathrm{~mm} /{ }^{\circ} \mathrm{C}$ ) (see Figure $5(\mathrm{~d})$ ). As introduced in $[14,16]$, when a point moves away from the SAR sensor along the LOS direction, the horizontal deflection of the point performs to be negative. Consequently, a negative thermal expansion coefficient indicates a greater horizontal deflection away from the SAR sensor than the positive vertical deflection, which leads the comprehensive negative deformation away from the sensor. With a higher horizontal deflection and a lower vertical deflection for a tall building, the total deflection induced by thermal expansion performs positive. In contrast, the thermal expansion of a low and long road is mainly with a negative deflection. Accordingly, the points with negative coefficient of thermal expansion perform to concentrate along the road. This is why the negative thermal expansion points distributed mainly along the road in Figure 5(d).

The thermal dilation parameters for the PS points distributed at Dongting Lake Bridge (area E in Figure 5(a)) 


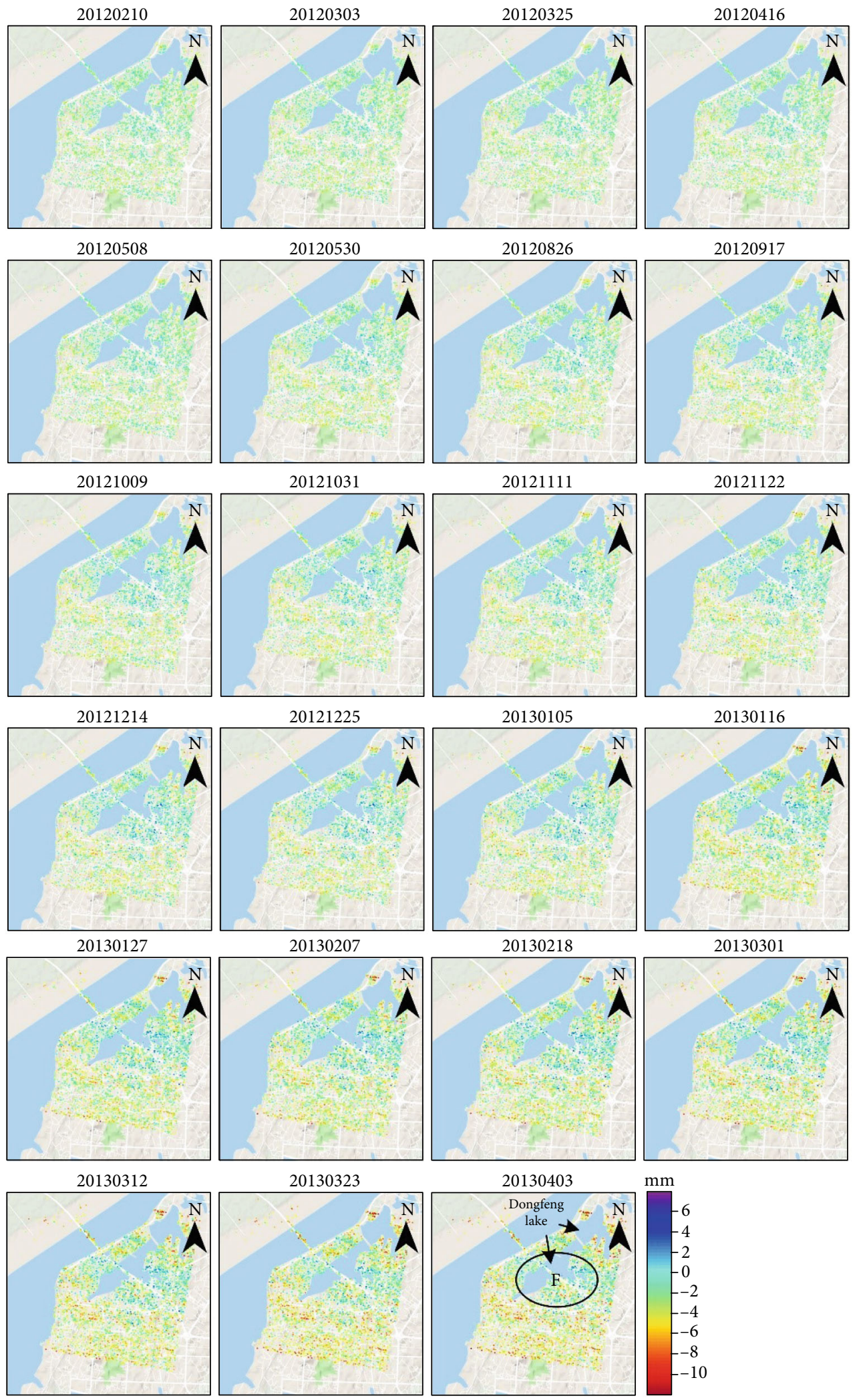

FIGURE 6: Time series deformation around Dongting Lake based on LM (referenced to 28 December 2011, $F$ represents a typical uplift area, which will be discussed later). 


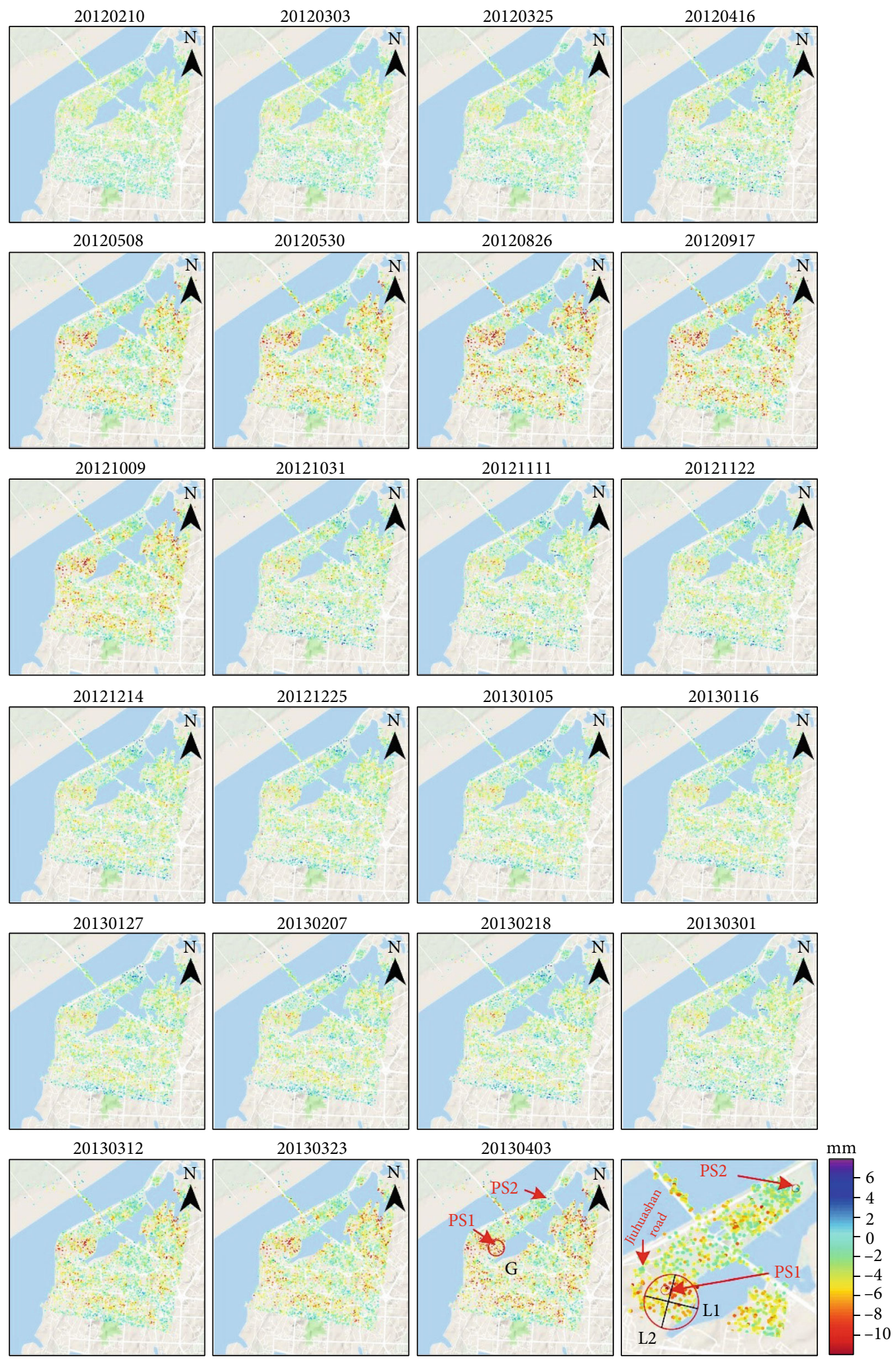

FIGURE 7: Time series deformation around Dongting Lake based on TESM (referenced to 28 December 2011, G is a typical subsidence bowl with transversal line L1 and longitudinal line L2, which will be discussed later).

were also obtained, which is displayed clearly in Figure 5(e). As the generated thermal dilation parameters can reflect the physical property of the observed objects, a rough function was used to estimate the corresponding thermal expansion coefficient of the bridge material, which can be expressed as [16] 


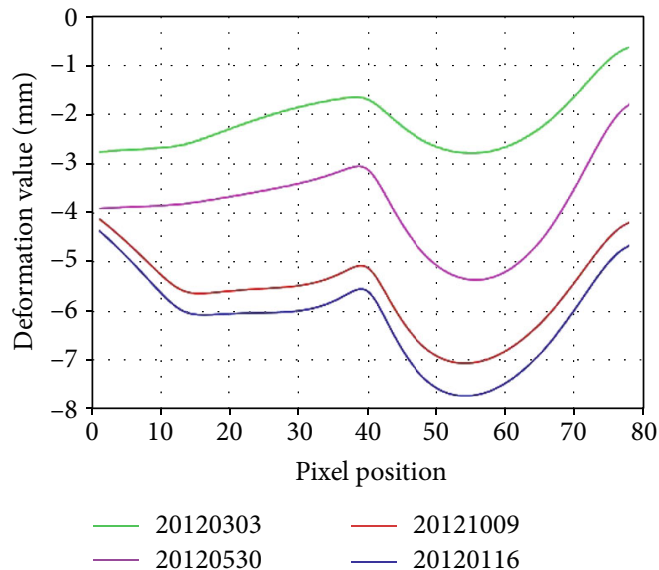

(a)

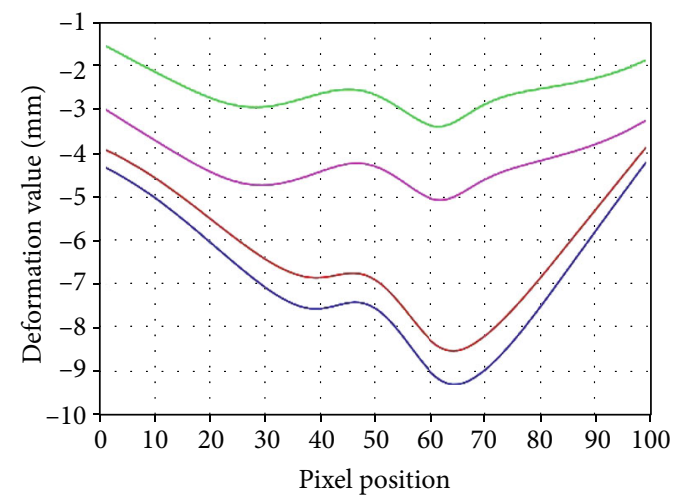

(b)

Figure 8: Profiles of the subsidence bowl in Figure 7. (a) Along the $l 1$ direction. (b) Along the $l 2$ direction.

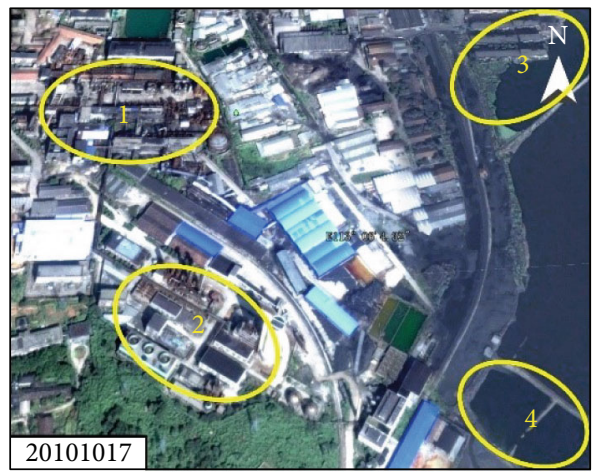

(a)

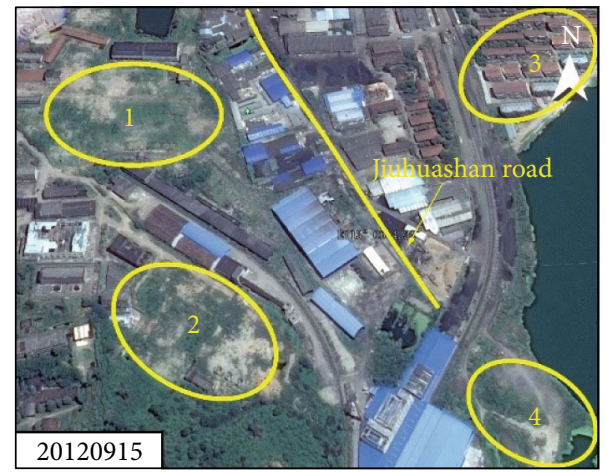

(b)

Figure 9: Enlarged map of the uplift area $G$ in Figure 7 with the optical map as background.

$$
K=\frac{\mathrm{Th}}{H},
$$

where $K$ and Th define the coefficient of thermal expansion and thermal dilation parameter, respectively; $H$ represents the height of main girder of the bridge reference to the bottom of pier. According to our estimation, the average expansion coefficient of the bridge materials is $11.6 \times$ $10^{-6} /{ }^{\circ} \mathrm{C}$. According to the collected construction design materials, the main girder of Dongting Lake bridge is made of C50 prestressed concrete with a continuous ribbed plate structure. The thermal expansion coefficient of this kind of concrete is approximately ranging from 6 $\times 10^{-6} /{ }^{\circ} \mathrm{C}$ to $13 \times 10^{-6} /{ }^{\circ} \mathrm{C}$. Therefore, our estimations show good consistency with the physical properties of bridge materials [30].

2.5.3. Overall Time Series Deformation. The generated two groups of overall time series deformation maps based on the LM and TESM are shown in Figures 6 and 7, respectively. From the spatial distribution, the surface deformation of LM along Dongfeng Lake (black ellipse $F$ ) shows slight uplift, approximately within the range of $3 \mathrm{~mm}$ to $7 \mathrm{~mm}$, while the urban hinterland was dominated by land subsidence, within the range of $5 \mathrm{~mm}$ to $13 \mathrm{~mm}$. The results based on the TESM were mainly orange, and the corresponding subsidence was approximately ranging from $2 \mathrm{~mm}$ to $6 \mathrm{~mm}$. In addition, it can be found from Figure 7 that there is an obvious subsidence funnel (see the red ellipse $G$ ) locates close to Dongfeng Lake and Jiuhuashan Road (shown in Figure 7), which was hidden in the generated results by LM. To further discuss and analyze the growing process of the typical subsidence bowls, profile analysis along the transversal and longitudinal directions (see the transversal line $l 1$ and longitudinal line $l 2$ in the last image of Figure 7) was carried out. The results are shown in Figure 8. According to our measurements, the peak subsidence along the $l 1$ direction was $6 \mathrm{~mm}$ and $8 \mathrm{~mm}$ on the 15th and 54th pixels, whereas $7 \mathrm{~mm}$ and $9 \mathrm{~mm}$ at the 38th and 63th pixels along $l 2$ direction. The maximum subsidence of $8 \mathrm{~mm}$ and $9 \mathrm{~mm}$ was detected at the 54th and 63th pixels along $l 1$ and $l 2$ directions, respectively. According to our investigation for the temporal optical images (shown as Figure 9) and the collected historical engineering materials of this area, we found that demolishment of some factory buildings (shown as areas 1 and 2 in Figure 9) and the lake reclamation project on some areas (shown as areas 3 and 4 in Figure 9) occurred during the period from 17 October 2010 to 15 September 2012. The subsiding phenomenon for 


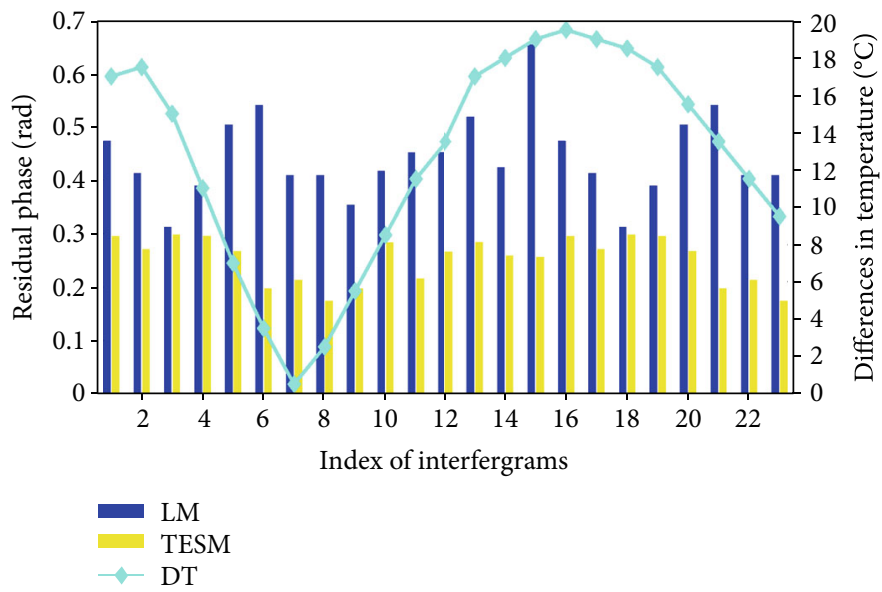

FIGURE 10: RMS of residual phases of a 23-interferogram comparison for TESM and LM (DT means the difference of temperature for each interferogram).

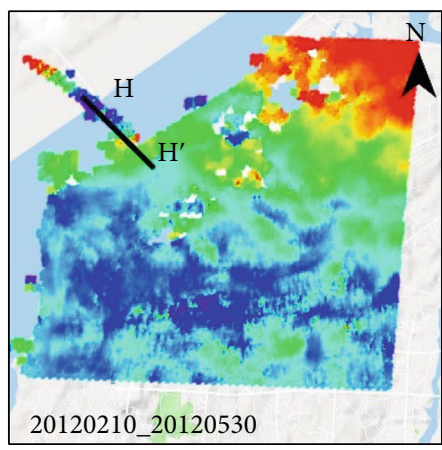

(a)

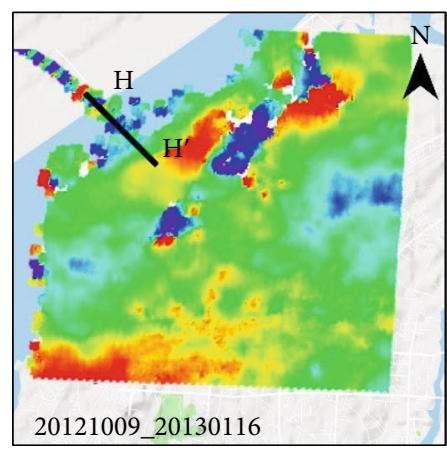

(c)

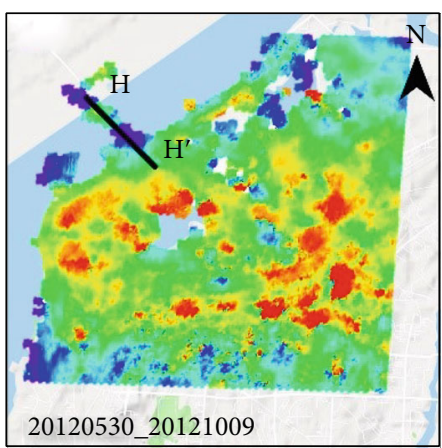

(b)

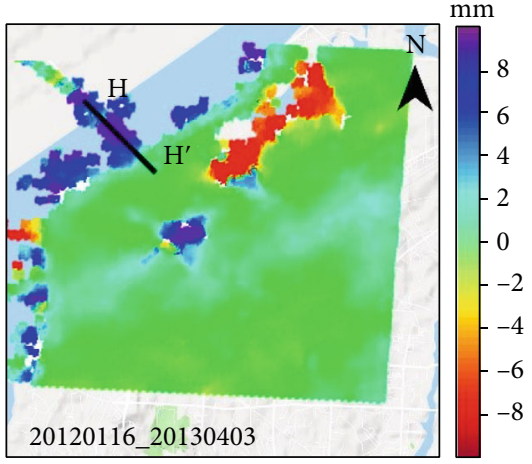

(d)

FIGURE 11: D-InSAR generated deformation pairs.

this area is suggested related to those engineering projects during this period.

2.5.4. Accuracy Assessment. In order to compensate for the unavailability of the external in situ deformation measurements over this area, the residual phase of each interferogram obtained through the TESM was compared with that of LM. According to [31], the fitting accuracy of a deformation model can be reflected by the residue phase $(\Delta \phi$ res in equation (1)). The smaller the residual phase is, the higher the accuracy of the selected model is. The root mean square (RMS) of the residual phases for all the interferograms is shown in Figure 10. It can be seen that for the two models, the total RMS of the residual phase is less than $0.7 \mathrm{rad}$, which indicates a good accuracy of deformation modeling. Comparatively, for the $6^{\text {th }}, 7^{\text {th }}, 8^{\text {th }}, 21^{\text {th }}, 22^{\text {th }}$, and $23^{\text {th }}$ images, the RMS of TESM was obviously lower than that of LM, and the total RMS for the TESM is $0.32 \mathrm{rad}$, whereas LM is $0.46 \mathrm{rad}$. It shows that the temporal evolution of deformation in this study area can be modeled more accurately by adding 


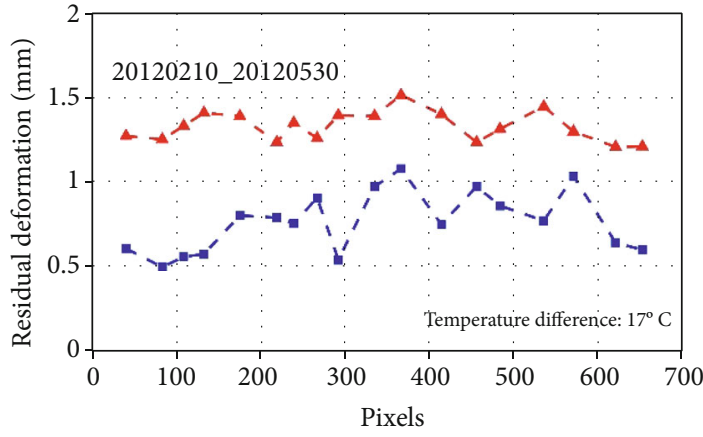

(a)

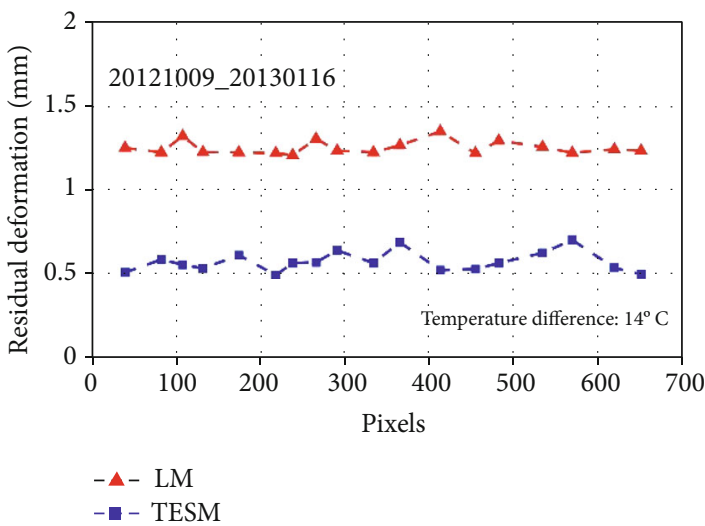

(c)

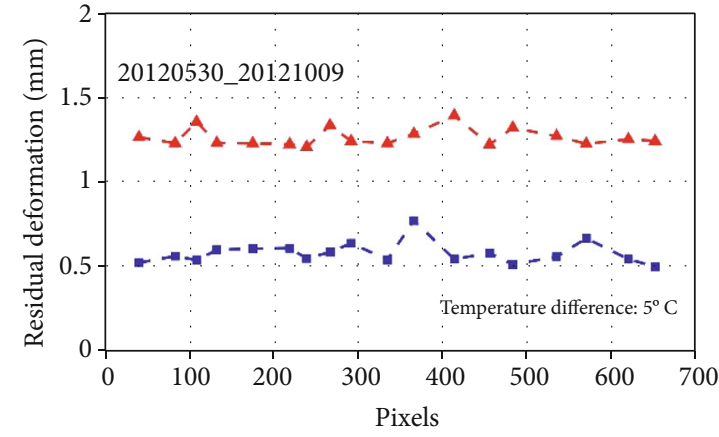

(b)

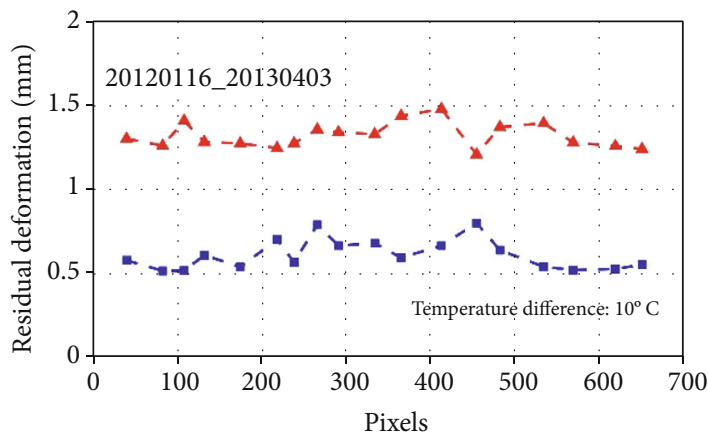

(d)

Figure 12: Residual deformation comparison of the two models along Section $\mathrm{H}-\mathrm{H}^{\prime}$.

a thermal expansion component into the traditional seasonal model.

To further evaluate the accuracy of the obtained deformation time series, the PSI derived deformation was compared with the results of D-InSAR processing. Four periods were selected, and the corresponding D-InSAR generated deformation pairs are displayed as Figure 11. The D-InSAR results along the section $\mathrm{H}-\mathrm{H}^{\prime}$ were extracted to compare with the PSI generated results, which are demonstrated in Figure 12. It can be noticed that the residual deformation of the TESM was obviously lower than that of LM. The deviation of TESM was lower than $0.8 \mathrm{~mm}$, while for LM, most of the pixels were higher than $1.2 \mathrm{~mm}$. The quantitative calculation of the mean value and root mean square error (RMSE) of the residuals are summarized in Table 2. It is easy to find that TESM shows a better performance, with a total RMSE of $\pm 1.1 \mathrm{~mm}$ for the entire observation period and an improvement of about 33\%. Moreover, earlier study introduced that the subsidence magnitude around Dongting Lake area was within $1 \mathrm{~cm}$, which is consistent with the magnitude obtained in this paper [32].

\section{Discussions}

3.1. Temporal Deformation Characteristics Based on TESM. From the temporal evolution shown by the time series deformation maps generated by TESM (see Figure 7), it can be seen that the results show a periodic temporal evolution.
TABLE 2: Mean residual and RMSE with comparison to D-InSAR derived subsidence (DT represents the differences of temperature).

\begin{tabular}{lccccc}
\hline Interferometric pairs & DT $\left({ }^{\circ} \mathrm{C}\right)$ & \multicolumn{2}{c}{$\begin{array}{c}\text { Mean } \\
\text { residual } \\
(\mathrm{mm})\end{array}$} & \multicolumn{2}{c}{ RMSE $(\mathrm{mm})$} \\
& & LM & TESM & LM & TESM \\
\hline $20120210-20120530$ & 17.0 & 1.3 & 0.8 & 1.9 & 1.5 \\
$20120530-20121009$ & -5.0 & 1.2 & 0.6 & 1.3 & 0.8 \\
$20121009-20130116$ & -14.0 & 1.2 & 0.6 & 1.3 & 0.7 \\
$20130116-20130403$ & 10.0 & 1.3 & 0.7 & 1.7 & 1.1 \\
\hline
\end{tabular}

From 3 March 2012 to 26 August 2012, a temporally subsiding trend dominated this area, with the accumulated subsidence up to $13 \mathrm{~mm}$ until 26 August 2012. From 26 August 2012 to 14 December 2012, a slow uplift trend dominated the deformation, with the maximum recovery accumulated to $14 \mathrm{~mm}$. The main reason for this periodic variation was supposed related to the local hydrogeological conditions and climatic factors. According to the working data of 402 geological team in Hunan Province, this area was with extremely well-developed water system and rick groundwater resources [32]. According to our in situ investigation, the shallow groundwater is closely connected with the major water systems. In rainy seasons, the water volume of rivers and lakes was increased by the precipitation. According to the statistics of the Meteorological Bureau, the precipitation from April to July in Yueyang was obviously serious, with 
TABLE 3: The proportion of each deformational component on PS1 and PS2.

\begin{tabular}{lccccc}
\hline $\begin{array}{l}\text { Feature } \\
\text { points }\end{array}$ & $\begin{array}{c}\text { Seasonal } \\
\text { component }\end{array}$ & $\begin{array}{c}\text { Thermal expansion } \\
\text { component }\end{array}$ & $\begin{array}{c}\text { Precipitation related } \\
\text { component }\end{array}$ & $\begin{array}{c}\text { Linear } \\
\text { component }\end{array}$ & $\begin{array}{c}\text { Residual } \\
\text { component }\end{array}$ \\
\hline PS1 & $79.7 \%$ & $11.2 \%$ & $3.2 \%$ & $1.7 \%$ & $4.2 \%$ \\
PS2 & $32.3 \%$ & $56.1 \%$ & $5.3 \%$ & $2.6 \%$ & $3.7 \%$ \\
\hline
\end{tabular}

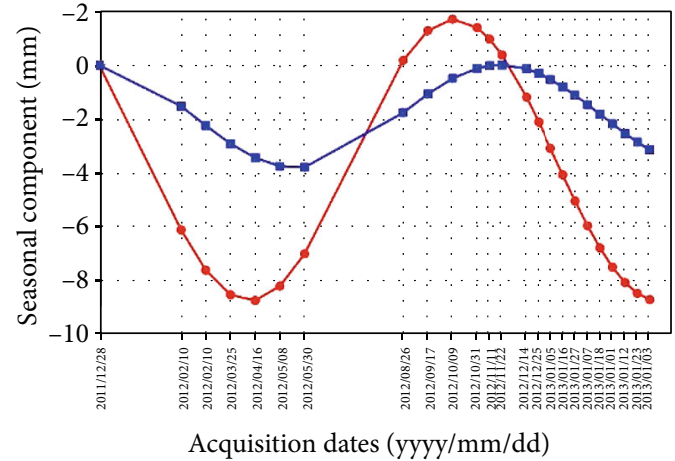

(a)

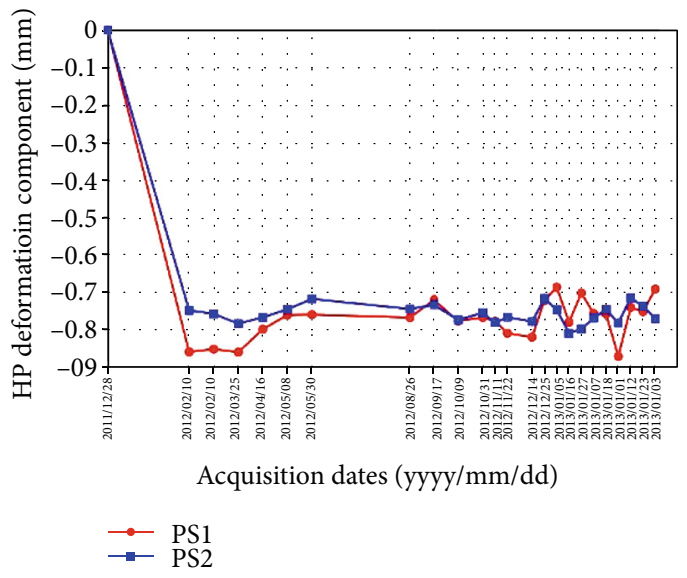

(c)

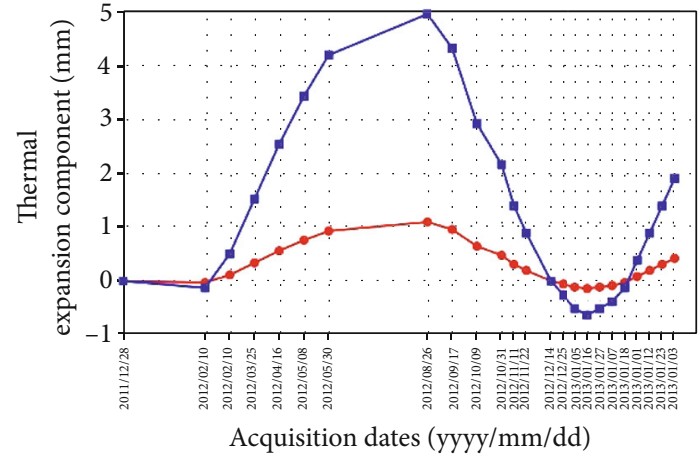

(b)

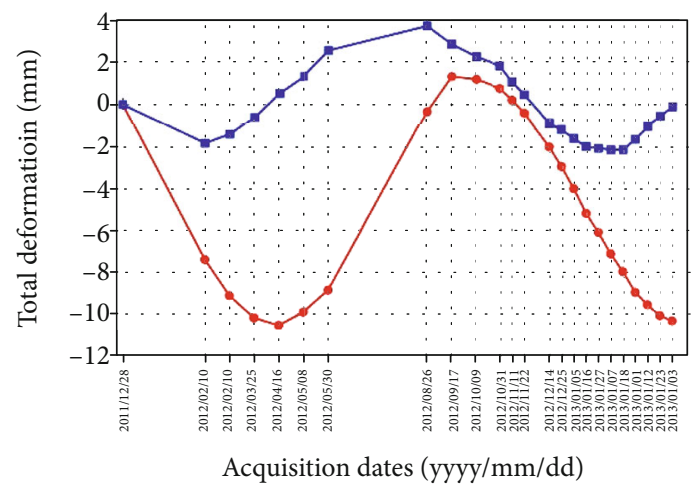

(d)

Figure 13: Time series deformation of the two feature points in Figure 7: (a) seasonal deformation component, (b) thermal expansion deformation component, (c) HP deformation component, and (d) total deformation.

the average precipitation higher than $150 \mathrm{~mm}$ (see Figure 3). Due to the increase of precipitation in summer, the groundwater was increased by the surrounding water system and the precipitation supply, which lead to obvious ground surface uplift around the lake area.

In order to clearly show the temporal evolution of deformation, two feature points located in the subsidence funnel and the uplift area were selected, respectively. The proportion of each component is shown in Table 3. For instance, for PS1, the deformation component related to the seasonal component accounted for $79.7 \%$, whereas the component related to the thermal expansion accounted for $11.2 \%$, and the precipitation deformation component occupied 3.2\%, the linear component accounted for $1.7 \%$, and the HP-deformation $4.2 \%$. For PS2, the isolated deformation component related to the seasonal component accounted for $32.3 \%$ of the total deformation, and the component related to thermal expansion accounted for $56.1 \%$. The precipitation deformation component and the linear component only accounted for $5.3 \%$ and $2.6 \%$, respectively. The HP-deformation isolated from the residual phase only occupied $3.7 \%$. We can see that the seasonal component and the thermal expansion component dominated the total deformation, followed with the precipitation deformation component, which indicate that the deformation of soft clay in the area was most significantly affected by the seasonal component and the thermal expansion. The time series deformation for the seasonal component and thermal expansion component of the two points is shown in Figure 13 quantitively. It can be seen that the deformation of PS1 is mainly subsiding with periodical fluctuation. The seasonal component dominated the total deformation of PS1, accounting for approximately $80 \%$. The max subsidence for PS1 was $10 \mathrm{~mm}$ occurred on 3 April 2013. In contrast, PS2 was dominated by the thermal expansion component (accounting for 56\%), thus following a temporal periodic variation, with the peak value accumulated to $4 \mathrm{~mm}$ on 

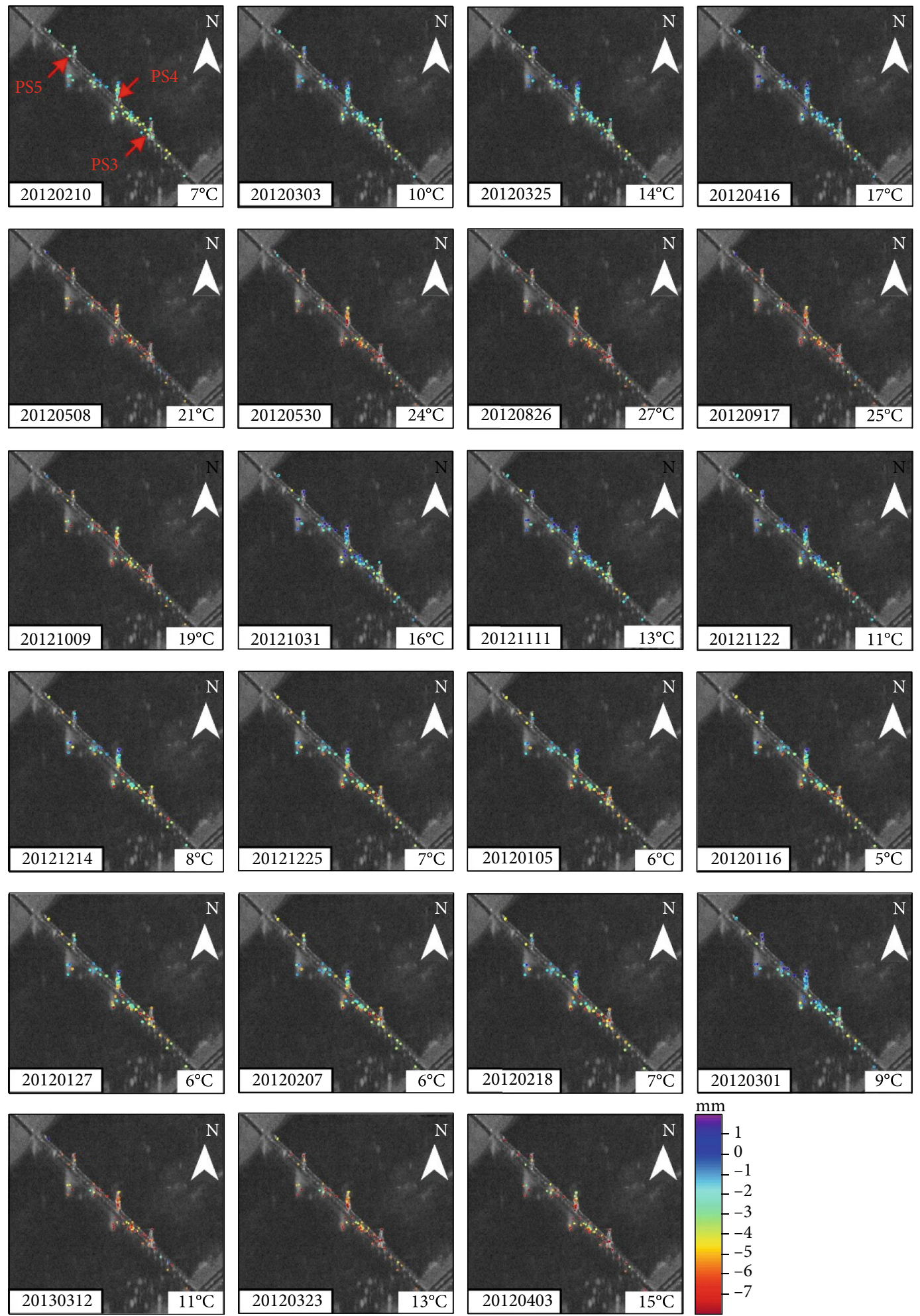

Figure 14: Overall deformation time series of Dongting Lake Bridge.

26 August 2012 and the max subsidence of $2 \mathrm{~mm}$ on 14 December 2012.

3.2. Deformation over Dongting Lake Bridge Based on TESM. During our experiment, 191 PS points were extracted from Dongting Lake Bridge, and the time series deformation is shown in Figure 14. The temperature mark for each subFigure in Figure 14 is the temperature difference for each interferometric period, which is used to get the average temperature in function (4). It is easy to find that the color of the PS points on the whole bridge was mainly yellow, which indicates a settlement trend, with the max subsidence of $12 \mathrm{~mm}$ 


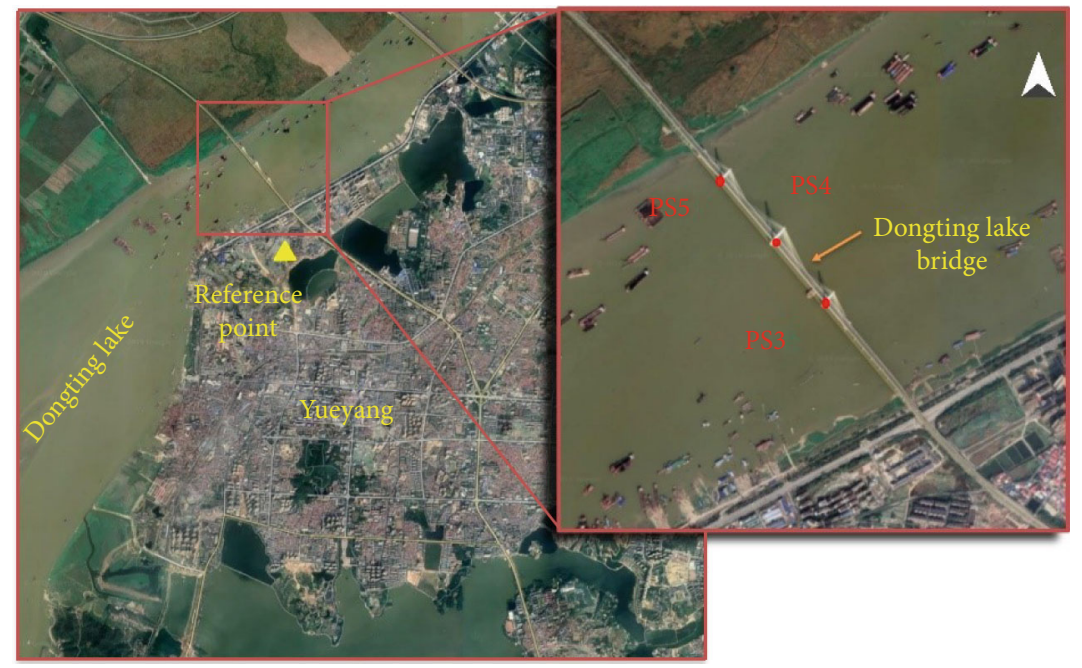

FIgURE 15: Location of feature points on Dongting Lake Bridge.

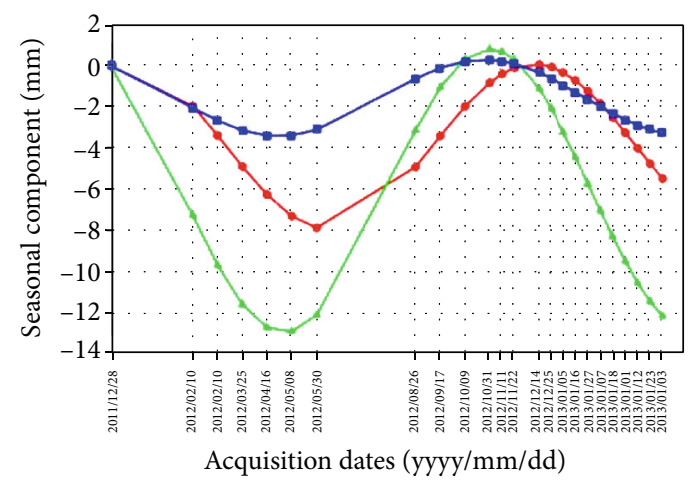

(a)

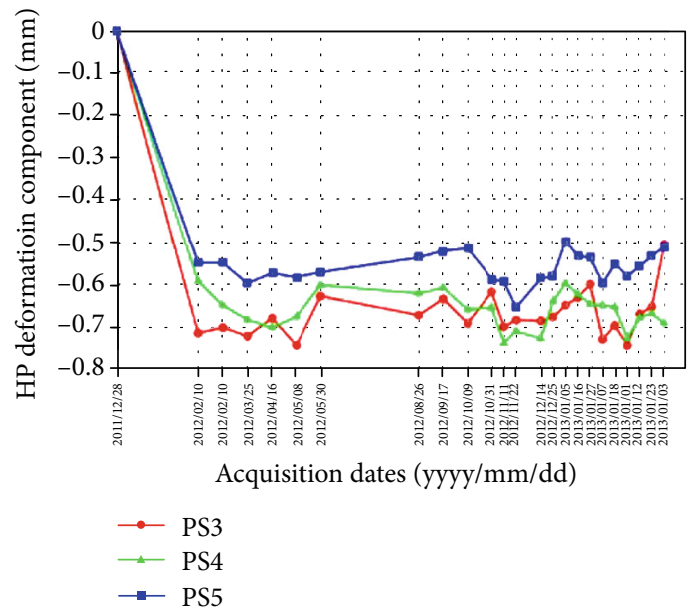

(c)

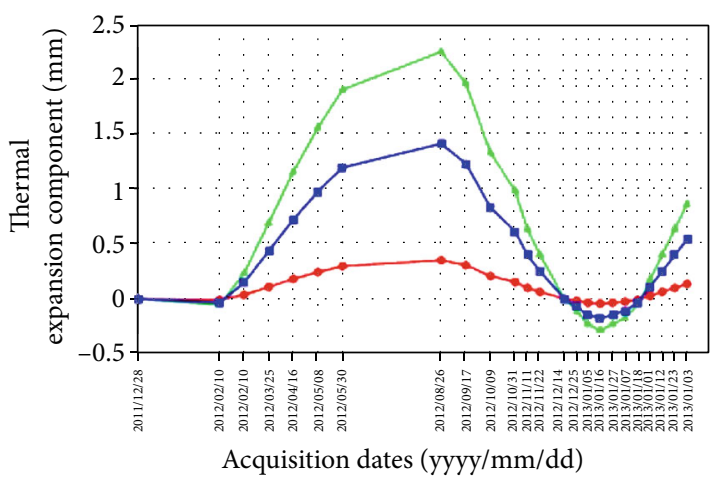

(b)

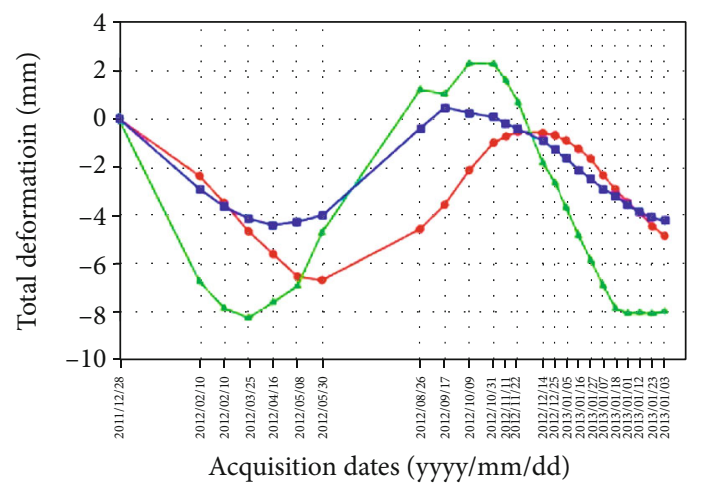

(d)

FIgURE 16: Time series deformation components at feature points on Dongting Lake Bridge: (a) seasonal deformation component, (b) thermal expansion deformation component, (c) HP deformation component, and (d) total deformation.

occurred at 26 August 2012. This is suggested related to the vertical expansion of the bridge pier as the increase of temperature. Moreover, the points at the top of the middle bridge tower showed a dominantly blue color while the points along the lower part of the bridge tower were yellow and red. This phenomenon suggested that the top of the middle bridge tower was affected by the tension of the stay cables on both sides, which induced a mainly horizontal movement rather than subsidence. Since we roughly treated the 3D deformation as the contribution of a single LOS deformation 


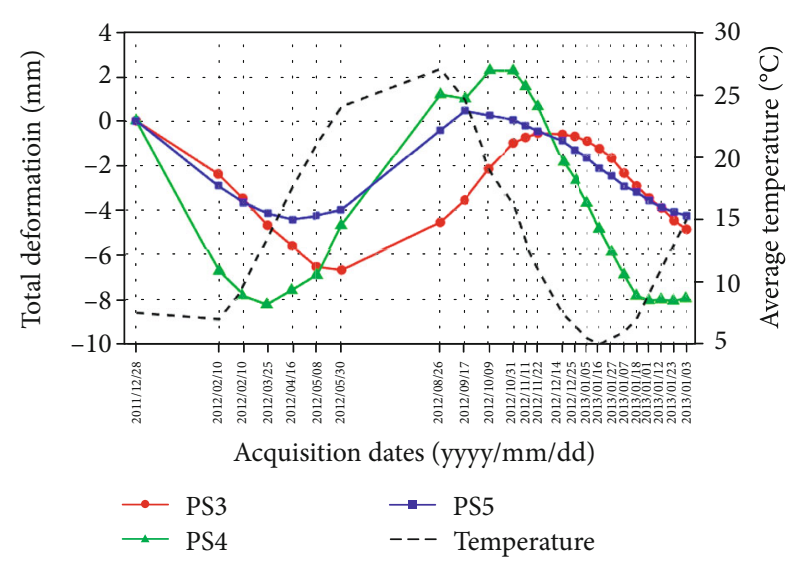

Figure 17: Correlation between the deformation of the feature points and the ambient temperature.

component, the final transferred vertical deformation of the points at the top of the middle tower showed a relatively uplift trend. From 9 October 2012, more orange points appeared at the segment from the middle tower to the south tower, with the max subsidence of $6 \mathrm{~mm}$, which occurred on 26 August 2012. Moreover, our results reflect that the PS points located close to both riversides were more stable than those at the center segment, which was related to the more steadily support of the piers in riversides. According to the design standard of the bridge, the maximum downward deflection of the middle span is $33.8 \mathrm{~cm}$, and the maximum downward deflection of the side span is $12.8 \mathrm{~cm}$. Consequently, according to the magnitude of our estimation, the total deformation induced by thermal expansion was within a controllable range, which indicates the bridge was under a relatively stable condition.

In order to further analyze the temporal evolution of the deformation along the bridge, three feature points were selected on three piers, which were indexed as PS3, PS4, and PS5 from the south to north (see the locations for the three PSs on Figure 15). PS3 is located at the south bridge tower, and the obtained time series deformation at PS3 is shown in Figure 16. It can be noticed that the deformation at PS3 is mainly subsidence. The seasonal component accounts for $80 \%$ of the total deformation, with the max value up to $-8 \mathrm{~mm}$. In contrast, the thermal expansion component accounts for $10 \%$ of the total deformation. The peak uplift of the thermal expansion component was up to $0.4 \mathrm{~mm}$ on 26 August 2012, whereas the maximum subsidence was $0 \mathrm{~mm}$ on 5 January 2013. According to our estimation from Figure 5(a), the thermal dilation parameter at point PS3 was $0.178 \mathrm{~mm} /{ }^{\circ} \mathrm{C}$. The total deformation shows an obvious periodical evolution, with the max subsidence of $6 \mathrm{~mm}$ on 30 May 2012.

Comparatively, PS4 and PS5 which are located at the middle and north bridge tower show a generally time series subsidence with periodical fluctuation. The thermal expansion component accounts for more than $30 \%$ of the total deformation, up to $2 \mathrm{~mm}$ for both the two targets. The maximum uplift of the thermal expansion component was $2.3 \mathrm{~mm}$ for PS4, whereas $1.5 \mathrm{~mm}$ for PS5, which occurred on 30 May 2012, respectively. The thermal dilation parameters for those two points were $0.323 \mathrm{~mm} /{ }^{\circ} \mathrm{C}$ and $0.294 \mathrm{~mm} /{ }^{\circ} \mathrm{C}$, respectively. The total deformation for the two points reached a maximum of $8 \mathrm{~mm}$ and $4 \mathrm{~mm}$ in August, respectively. Similarly, with an approximately $7 \mathrm{~mm}$ recovery, the total deformation was only $1 \mathrm{~mm}$ on 14 December 2012. Obviously, the periodical fluctuation of the deformation time series depended on the seasonal component.

As shown in Figure 14, we found that the total deformation shows relationship with the temperature difference for each interferometric period. In order to further explore the correlation between the total deformation and the temperature, we carried out a correlation analysis, which is shown in Figure 17. Due to the unavailability of detail bridge surface temperature, we only collected external air temperature in Yueyang City to conduct the study. It can be noticed from the figure that the vertical deformation of the bridge was highly correlated with the temperature, with the correlation coefficients of $0.89,0.87$, and 0.79 , respectively, for the three targets.

\section{Conclusions}

A long-term deformation investigation over the area with densely distributed infrastructures around Dongting Lake was presented based on PSI technology using 24 TerraSAR$\mathrm{X}$ images from December 2011 to April 2013. Considering the unavoidable influence of the thermal expansion over the infrastructures for TerraSAR X satellite image and the seasonal environmental factors for the lakeside area, TESM was proposed to replace the traditional LM. A comparative analysis has been conducted for the spatial-temporal investigation for the deformation time series. Spatially, subsidence mainly dominated the inland area on the north part of the study area, while the area along Dongfeng Lake performed a slight uplift trend. An obvious subsidence funnel, located close to Jiuhuashan Road in Yueyang Tower District, was detected in the result of TESM, which was hidden in that of LM. In addition, a generally periodical subsiding variation was detected through TESM, with a maximum subsidence up to $18 \mathrm{~mm}$ occurred on 26 August 2012. From the generated thermal dilator parameter map, the thermal expansion coefficient for Dongting Lake Bridge was estimated as 11.6 $\times 10^{-6} /{ }^{\circ} \mathrm{C}$, which is consistent with the physical properties of the bridge concrete. The results of three feature points at the bridge show that the maximum subsidence value of the bridge was $8 \mathrm{~mm}$, which occurred on 26 August 2012, showing the whole bridge was under a stable condition during the entire observation period.

In order to compensate for the unavailability of external in situ geodetic measurements over this area, the phase residuals and D-InSAR generated subsidence were utilized to verify the accuracy of the obtained deformation time series. The results show that with adding the thermal expansion component, the RMS of the residual phase performed an improvement of $30 \%$. The RMS compared to the DInSAR results for the two models is $1.7 \mathrm{~mm}$ and $1.1 \mathrm{~mm}$, respectively, which indicated an increasement of $33 \%$ for TESM. The consistence with the settlement magnitude over this area 
introduced in earlier study work also verified the reliability of our result.

\section{Data Availability}

The TerraSAR-X satellite images used in this paper are provided by the German Space Center (DLR) (Data Order Program Project: MTH3393).

\section{Conflicts of Interest}

The authors declare no conflict of interest.

\section{Acknowledgments}

This work was supported by the National Natural Science Foundation of China under Grant (No. 41701536, No. 61701047, and No. 41904003), Natural Science Foundation of Hunan Province under Grant (No. 2017JJ3322, No. 2019JJ50639), Key Project of Education Department of Hunan Province under Grant (No. 18A148), Project of Education Department of Hunan Province under Grant (No. 16C0034), and Open Fund of Engineering Laboratory of Spatial Information Technology of Highway Geological Disaster Early Warning in Hunan Province under Grant (No. kfj190601).

\section{References}

[1] D. Bai, J. Li, T. Ma et al., "Tectonic-sedimentary landforms classification of middle segment of east quaternary JianghanDongting Basin," Scientia Geographica Sinica, vol. 30, no. 2, pp. 236-241, 2010.

[2] W. Tang, M. Liao, and P. Yuan, "Atmospheric correction in time-series SAR interferometry for land surface deformation mapping - a case study of Taiyuan, China," Advances in Space Research, vol. 58, no. 3, pp. 310-325, 2016.

[3] Z. Yang, F. Schmid, and C. Roberts, "Assessment of railway performance by monitoring land subsidence," in Proc. IETRCM, Birmingham, UK, September 2014.

[4] D. Perissin, Z. Wang, and H. Lin, "Shanghai subway tunnels and highways monitoring through Cosmo-SkyMed persistent Scatterers," ISPRS Journal of Photogrammetry and Remote Sensing, vol. 73, pp. 58-67, 2012.

[5] S. W. Kim, S. Wdowinski, T. H. Dixon, F. Amelung, J. W. Kim, and J. S. Won, "Measurements and predictions of subsidence induced by soil consolidation using persistent scatterer InSAR and a hyperbolic model," Geophysical Research Letters, vol. 37, no. 5, article L05304, 2010.

[6] F. Chen, H. Lin, Z. Li, Q. Chen, and J. Zhou, "Interaction between permafrost and infrastructure along the QinghaiTibet Railway detected via jointly analysis of C- and L-band small baseline SAR interferometry," Remote Sensing of Environment, vol. 123, pp. 532-540, 2012.

[7] D. Cusson, K. Trischuk, D. Hébert, G. Hewus, M. Gara, and P. Ghuman, "Satellite-Based InSAR monitoring of highway bridges: validation case study on the North Channel Bridge in Ontario, Canada," Transportation Research Record: Journal of the Transportation Research Board, vol. 2672, no. 45, pp. 7686, 2018.
[8] P. Ma, T. Li, C. Fang, and H. Lin, "A tentative test for measuring the sub-millimeter settlement and uplift of a high-speed railway bridge using COSMO-SkyMed images," ISPRS Journal of Photogrammetry and Remote Sensing, vol. 155, pp. 1-12, 2019.

[9] Y. Zhao, L. Wang, Y. Liu, Z. Tian, and Y. Peng, "Study on the monitoring of urban bridge shape variables based on remote sensing data and PS-InSAR," Construction Science and Technology, vol. 4, pp. 55-58, 2016.

[10] X. Xing, L. Chen, Z. Yuan, and Z. Shi, “An improved timeseries model considering rheological parameters for surface deformation monitoring of soft clay subgrade," Sensors, vol. 19, no. 14, article 3073, 2019.

[11] C. Qu, X. Shan, X. Song, G.-F. Zhang, G.-H. Zhang, and L. Guo, "The PSInSAR technique and its application to the study on crustal deformation of the Haiyuan fault zone," Chinese Journal of Geophysics, vol. 54, no. 4, pp. 984-993, 2011.

[12] D. Ge, W. Yan, X. Guo, W. Yi, and X. Ye, "Land subsidence investigation along railway using permanent scatterers SAR interferometry," in Proc. IEEE-IGARSS, Boston, MA, USA, July 2008.

[13] T. Li, G. Liu, H. Jia et al., “An improved multi-temporal InSAR method for increasing spatial resolution of surface deformation measurements," ISPRS-SSG, vol. XL-7/W2, pp. 145-150, 2013.

[14] P. Ma, H. Lin, H. Lan, and F. Chen, "Multi-dimensional SAR tomography for monitoring the deformation of newly built concrete buildings," ISPRS Journal of Photogrammetry and Remote Sensing, vol. 106, pp. 118-128, 2015.

[15] X. Qin, L. Zhang, X. Ding, M. Liao, and M. Yang, "Mapping and characterizing thermal dilation of civil infrastructures with multi-temporal X-band synthetic aperture Radar interferometry," Remote Sensing, vol. 10, no. 6, p. 941, 2018.

[16] O. Monserrat, M. Crosetto, M. Cuevas, and B. Crippa, "The thermal expansion component of persistent scatterer interferometry observations," IEEE Geoscience and Remote Sensing Letters, vol. 8, no. 5, pp. 864-868, 2011.

[17] M. Crosetto, O. Monserrat, M. Cuevas-González, N. Devanthéry, G. Luzi, and B. Crippa, "Measuring thermal expansion using X-band persistent scatterer interferometry," ISPRS Journal of Photogrammetry and Remote Sensing, vol. 100, pp. 84-91, 2015.

[18] X. Qin, M. Liao, M. Yang, and L. Zhang, "Monitoring structure health of urban bridges with advanced multi-temporal InSAR analysis," Annals of GIS, vol. 23, no. 4, pp. 293-302, 2017.

[19] J. Jiang, Q. Huang, Y. Wang, Q. Wang, and J. Guo, “Application of InSAR Technology in Deformation Monitoring of Yangtze River Bridge of Anqing Railway," Journal of Gansu Sciences, vol. 30, no. 6, pp. 73-77, 2018.

[20] A. Ferretti, C. Prati, and F. Rocca, "Permanent scatterers in SAR interferometry," IEEE Transactions on Geoscience and Remote Sensing, vol. 39, no. 1, pp. 8-20, 2001.

[21] P. J. G. Teunissen, "The least-squares ambiguity decorrelation adjustment: a method for fast GPS integer ambiguity estimation,” Journal of Geodesy, vol. 70, no. 1-2, pp. 65-82, 1995.

[22] B. M. Kampes and R. F. Hanssen, "Ambiguity resolution for permanent scatterer interferometry," IEEE Transactions on Geoscience and Remote Sensing, vol. 42, no. 11, pp. 24462453, 2004.

[23] A. Ferretti, C. Prati, and F. Rocca, "Nonlinear subsidence rate estimation using permanent scatterers in differential SAR 
interferometry," IEEE Transactions on Geoscience and Remote Sensing, vol. 38, no. 5, pp. 2202-2212, 2000.

[24] S. S. Li, Z. W. Li, J. Hu, Q. Sun, and X. Y. Yu, "Investigation of the seasonal oscillation of the permafrost over Qinghai-Tibet Plateau with SBAS-InSAR algorithm," Chinese Journal of Geophysics, vol. 56, no. 5, pp. 1476-1486, 2013.

[25] J. Wei, Z. Li, J. Hu, G. Feng, and M. Duan, “Anisotropy of atmospheric delay in InSAR and its effect on InSAR atmospheric correction," Journal of Geodesy, vol. 93, no. 2, pp. 241-265, 2019.

[26] J. Liao, D. Li, J. Hu, and H. Zhou, "Design of three tower cablestayed bridge of Dongting Lake Bridge in Yueyang," in Proc. AEM-CHS, pp. 222-228, Yinchuan, Ningxia, China, 2001.

[27] J. H. T. Bbates, "A polynomial method for fitting continuous distributions of exponentials with positivity constraint," IEEE Transactions on Biomedical Engineering, vol. BME-32, no. 7, pp. 478-484, 1985.

[28] China Meterological Administration, "Historical weather in Yueyang," http://lishi.tianqi.com/yueyang/index.html.

[29] M. Esmaeili and M. Motagh, "Improved persistent scatterer analysis using amplitude dispersion index optimization of dual polarimetry data," ISPRS Journal of Photogrammetry and Remote Sensing, vol. 117, pp. 108-114, 2016.

[30] J. Huang, S. Wu, and D. Shen, "E xperimental study on thermal expansion coefficient of different type coarse aggregates concrete at early ages," Structural Engineers, vol. 26, no. 3, pp. 154-158, 2010.

[31] X. Xing, H. C. Chang, L. Chen, J. Zhang, Z. Yuan, and Z. Shi, "Radar interferometry time series to investigate deformation of soft clay subgrade settlement-a case study of Lungui Highway, China," Remote Sensing, vol. 11, no. 4, p. 429, 2019.

[32] D. Jiang, S. Huang, W. Zhang, and D. Yu, "A discussion on the evolution of the Dongting Lake based on geo-environmental remote sensing investigation and monitoring data," Remote Sensing for Land \& Resources, vol. 22, Supplement 1, pp. 124-129, 2010. 